\title{
Formação para o ensino agrícola nos Centros de Treinamento de Professores e de Auxiliares Rurais (1952-1963)*
}

\author{
IRAÍDE MARQUES DE FREITAS BARREIRO \\ Universidade Estadual Paulista
}

\section{INTRODUÇÃO}

A partir de 1945, a história do ensino agrícola no Brasil foi associada à extensão rural - designação "oriunda dos Estados Unidos, que carrega consigo a valoração de agregar medidas para elevar o nível de vida no meio rural, tendo como alvo o agricultor" (Fonseca, 1985, p. 39) - em programas estabelecidos por meio de acordos bilaterais. $\mathrm{O}$ ensino agrícola foi valorizado tanto para a formação de técnicos agrícolas para instruir os habitantes do campo quanto para formar professoras rurais. Nesse caso, o ensino agrícola compunha o ensino regular oferecido às alunas, futuras professoras rurais, nos centros de treinamento, sendo posteriormente ministrado às crianças, aos jovens e aos adultos analfabetos nas escolas rurais.

Este artigo analisou as finalidades do ensino agrícola proposto e desenvolvido pela Campanha Nacional de Educação Rural (CNER) (1952-1963) às professoras

* Texto apresentado no Grupo de Trabalho História da Educação (GT-02), da 35a Reunião Anual da Associação Nacional de Pós-Graduação e Pesquisa em Educação (ANPEd), realizada em Porto de Galinhas/Ipojuca (PE), de 21 a 24 de outubro de 2012. Pesquisa realizada após o doutorado, fundamentada em expressivas fontes documentais conseguidas em vários arquivos, bibliotecas e jornais, em diferentes estados. 
rurais nos Centros de Treinamento de Professores e de Auxiliares Rurais. ${ }^{1}$ Para tanto, foram analisados os conteúdos dos programas de ensino desses cursos, publicados no volume 10 (especial) da Revista da Campanha Nacional de Educação Rural,1961/1962, que tratou da "Estruturação de um centro regional federal de treinamento de professores rurais". O volume reúne apresentação rica dos programas de ensino para os cursos de treinamento e de habilitação para atuais e futuras professoras rurais, com descrição de conteúdos, de atividades de estágios e fotos.

O ensino agrícola, parte integrante da educação rural, tinha a prerrogativa de formar o homem do campo numa perspectiva ampliada, para além da alfabetização, a fim de fixá-lo no campo, e igualmente a professora, em razão da falta de docentes formadas para ministrar aulas no meio rural.

O ensino regular no meio rural surgiu no fim do II Império (1870-1880), às vésperas da República, e se instalou amplamente na primeira metade do século XX, em consonância com a própria evolução das estruturas socioagrárias do Brasil e o fim formal da escravidão em 1888. Essas transformações passaram então a requerer mão de obra especializada no campo. Em compensação, o incentivo da industrialização a partir dos anos 1930 estimulou a migração campo-cidade, passando a se constituir em um sério problema social. Com isso, a educação rural passou a assumir, cada vez mais, a estratégia de fixar o homem rural, e o ensino agrícola foi se impondo aos poucos para suprir necessidades econômicas que iam surgindo no setor da economia. Desse modo, ao longo da história, "o ensino agrícola afeta, direta ou indiretamente, todos os programas que, no Brasil, vinculam-se à educação rural, de modo geral. Outro aspecto que também deve ser realçado é a função normativa que o ensino regular rural exerce na educação agrícola de modo geral" (Calazans, 1979, p. 51). Essa função esteve presente na legislação específica do ensino agrícola regular, de acordo com as condições da agricultura do país e de seus recursos humanos. Os principais antecedentes históricos da criação da CNER qualificam melhor o significado dos objetivos pretendidos por este texto, bem como resgatam a história da formação de professoras rurais, tão pouco conhecida.

A educação rural sistematizada teve como marco a década de 1920, quando as classes dominantes passaram a se preocupar com a crescente migração rural-urbana, por significar ameaça à estabilidade social, agravada pela desqualificação profissional dessa população migratória. Entre 1880 e 1920, o número de trabalhadores das fábricas cresceu significativamente, e estes passaram a reivindicar direitos de cidadãos por meio de greves (Maia,1982, p. 5). Desse modo, a valorização do meio rural deu-se por intermédio da educação, orientada pelo ruralismo pedagógico - tendência importante entre as décadas de 1930 e 1940 -, que atingiu particularmente o ensino regular. "Buscava-se utilizar a escola para reforçar os valores rurais da civilização

1 Ao longo da história educacional, a terminologia para designar cursos para a formação de professores foi sendo modificada de "curso de treinamento para professores" para: "curso de reciclagem", "curso de capacitação", "formação em serviço" e, atualmente, "formação continuada", significando um processo contínuo na formação docente. 
brasileira, para criar uma consciência agrícola e assim se constituir num instrumento de fixação do homem ao campo" (Tanuri, 2000, p. 75).

No entanto, a educação de adultos como problema de caráter nacional apareceu nos últimos anos do Estado Novo (1937-1945), ao se criar programas específicos tratados em duas fases: antes da década de 1940 e posterior a ela, mais precisamente em 1945, quando a educação de adultos ganhou força pelo empreendimento da União.

$\mathrm{Na}$ primeira fase, o ensino rural constituiu-se em iniciativas de erradicação do analfabetismo com oferta de instrumental técnico para efetivar a fixação do homem no campo e responder a interesses regionais, com o patrocínio de entidades governamentais ou particulares, com legislação vaga. Embora regulamentado por normas educacionais urbanas, o ensino rural ganhou especificidades: no ensino de primeiro grau foram enfatizadas as atividades agropecuárias como iniciação para o trabalho; no segundo grau destacaram-se as atividades profissionais técnicas que priorizavam agronomia, veterinária, silvicultura, entre outras; o ensino superior priorizava a formação de engenheiros agrônomos, médicos, veterinários, sanitaristas rurais etc. (Calazans, 1979, p. 52).

A partir de 1940 (segunda fase), o ruralismo pedagógico perdeu relevância. A educação rural tornou-se pauta nas campanhas comunitárias, fundamentadas no desenvolvimento de comunidade, ${ }^{2}$ cuja adoção esteve ligada aos convênios estabelecidos com os Estados Unidos (EUA), como estratégias de ação na educação rural, extensiva ao trabalhador rural adulto, não se restringindo somente à escola (Fonseca, 1985, p. 56).

Em 1938, o decreto n. 580 criou o Instituto Nacional de Estudos Pedagógicos (INEP) para promover estudos e centralizar informações da educação nacional, financiar a construção de escolas para o ensino elementar, conceder bolsas de estudos para o aperfeiçoamento de pessoal técnico relacionado ao ensino primário e planejamento para o ensino supletivo, cuja determinação origina a criação de campanhas de educação de adultos a partir de 1947 (Paiva, 1987, p. 140). Em agosto de 1945, o Fundo Nacional do Ensino Primário (FNEP) passou a incentivar a difusão do ensino elementar e a educação de adultos, valorizados com o fim da II Guerra Mundial e a criação da Organização das Nações Unidas para a Educação, a Ciência e a Cultura (UNESCO); no plano nacional, ocorreu a derrubada do Estado Novo.

O empenho da UNESCO no combate ao analfabetismo não se restringiu à transmissão de técnicas elementares da leitura e da escrita, mas definiu a educação de base, também conhecida como educação fundamental. ${ }^{3}$ No caso de campanhas,

2 Pautado pelo conceito societário regido pela harmonia e equilíbrio, foi definido pela Organização das Nações Unidas (ONU), em 1956, como um "[...] processo através do qual os esforços do próprio povo se unem aos das autoridades governamentais, com o fim de melhorar as condições econômicas, sociais e culturais das comunidades, para integrar essas comunidades na vida nacional e capacitá-las a contribuir plenamente para o progresso do país" (Ammann, 1987, p. 32).

3 A educação fundamental foi proposta e patrocinada pela UNESCO, enquanto a educação de base teve origem predominante francesa, com vínculos cristãos. No Brasil 
houve uma conjugação entre esses dois modelos e, segundo Carlos Rodrigues Brandão (1980, p. 5), tal associação procurou atender aos interesses de governantes com o intuito de manter sob controle a organização popular desses grupos.

\section{A CNER NOS ACORDOS BILATERAIS}

A nova conjuntura internacional, instaurada após a II Guerra Mundial, propiciou o estabelecimento de diferentes acordos para assegurar desenvolvimento econômico profícuo aos países mais pobres. Por meio da Organização das Nações Unidas (ONU), os EUA passaram a trabalhar para garantir a "ordem social" e preservar o "mundo livre". O governo americano propôs extenso programa de assistência técnica aos países pobres, especialmente à América Latina, cuja ação extensionista foi apresentada pelos governos locais, em convênios com agências americanas de extensão rural (Ammann, 1987, p. 29-30).

Com a criação da UNESCO, em 1945, no clima ideológico do pós-guerra, a educação foi defendida como estratégia para elevar as condições de vida e combater a pobreza. No Brasil, foram criados programas nacionais para a educação de adultos analfabetos - sob a designação de Campanhas - para promover o desenvolvimento comunitário social e a expansão econômica do país. Naquele mesmo ano, firmaram-se acordos bilaterais entre o Ministério da Agricultura brasileiro e a Inter-American Educational Foundation, Inc. (cooperação subordinada ao Office of Inter-American Affairs), agência americana que propunha estabelecer "maior aproximação interamericana, mediante intercâmbio intensivo de educação, ideias e métodos pedagógicos entre os países" (idem, p. 31). Nesse contexto, sugeriu-se a adoção de missões rurais ${ }^{4}$ para o campo e o uso da estratégia de desenvolvimento de comunidade. $\mathrm{Na}$ "América Latina, as proposições da ONU serão assumidas e repercutirão através da CEPAL - Comissão Econômica para a América Latina" (Aguiar, 1985, p. 71).

Desse acordo resultou a criação da Comissão Brasileira Americana de Educação das Populações Rurais (CBAR), composta por técnicos americanos e brasileiros para executarem o programa. Os EUA disponibilizaram especialistas em educação rural, concederam bolsas de estudo para brasileiros naquele país e, com o

e particularmente, em relação à CNER, a orientação pedagógica combinou essas duas formas de educação, associadas ao desenvolvimento de comunidade. Tal associação procurou atender aos interesses de governantes no intuito de manter sob controle a organização popular desses grupos (Brandão, 1980, p. 5).

4 As Missões Culturais no México nasceram em 1922, após o triunfo da revolução social, com o intuito de formar pedagogicamente voluntários para trabalhar na zona rural. Em 1938 foram abolidas e relançadas em 1943, sob novas bases, como missão rural, “[...] para constituir um verdadeiro organismo de educação extra-escolar, capaz de exercer ação decisiva e direta sobre o indivíduo, a família e a comunidade, tendo em vista a melhoria das precárias condições de vida do povo" (Bonilla Segura, 1950, p. 54). 
apoio da UNESCO, foi criada a CNER, decorrente da experiência de Itaperuna, desenvolvida em 1951, no estado do Rio de Janeiro. ${ }^{5}$

Patrocinado pelo governo brasileiro, UNESCO e União Pan-Americana, em 1949 foi realizado o Seminário Interamericano de Educação de Adultos no Brasil. Estiveram presentes representantes de países experientes em desenvolvimento de comunidade, como México, Venezuela e Guatemala, para discutirem as bases para um sistema de trabalho compatível com as ideias internacionais para a América Latina (Paiva, 1987, p. 194-197). Nos anos de 1950, a Inglaterra criou o Programa Colombo, os EUA expandiram o Programa Truman, que subsidiava o Programa Ponto IV, considerado um "auxílio mais eficiente, como meio de combater o comunismo, cuja infiltração chegou, em certo momento, a preocupar seriamente os líderes democráticos" (O Ponto IV..., 1952, p. 5).

Nesse contexto, foi criada a CNER, em 1952, no governo de Getúlio Vargas, oficializada em 1956 na gestão de Juscelino Kubitschek e extinta em 1963, juntamente com as demais campanhas do Ministério da Educação (MEC). Seu objetivo principal foi adequar os habitantes rurais ao novo modelo de desenvolvimento para torná-los cidadãos e "elevar seus padrões culturais"(Lima, 1954, p. 131). A longa descrição do engenheiro agrônomo Miguel Alves de Lima, ao realizar levantamento geográfico para a instalação de uma missão rural no estado de Alagoas, é rica e contraditória. Enquanto "colonizador", registra que "os homens simples do meio rural se degeneram espiritualmente de geração a geração" (idem, p. 130), numa referência ao baixo padrão de cultura desse meio. Em contrapartida, denuncia a exploração sofrida pelo pequeno agricultor, submetido aos "sistemas de arrendamentos [da terra] escorchantes, determinantes do baixo padrão de vida" (idem, ibidem). Por tudo isso, coube à CNER,

[...] difundir a educação de base no meio rural brasileiro, [...] levar aos indivíduos e às comunidades os conhecimentos teóricos e técnicos indispensáveis a um nível de vida compatível com a dignidade humana e com os ideais democráticos, conduzindo as crianças, os adolescentes e os adultos a compreenderem os problemas peculiares ao meio em que vivem, a formarem uma idéia exata de seus deveres e direitos individuais e cívicos e a participarem eficazmente do progresso econômico e social da comunidade a que pertencem. (Regulamentação..., 1956, p. 10)

5 Embora seja consensual entre estudiosos da CNER a sua derivação da experiência de Itaperuna, é preciso ponderar que o posicionamento do primeiro coordenador da CNER, o sociólogo José Arthur Rios, em entrevista a mim concedida em 4 de abril de 1996, na cidade de São Paulo, foi o de que a CNER não decorreu da experiência de Itaperuna, pois naquele momento havia uma rivalidade política entre os Ministérios da Agricultura e da Educação. Sua versão foi que "interessava ao presidente Getúlio Vargas o apoio do ministro da Educação Simões Filho, por motivos políticos”, e com isso a CNER prosperou. Já em relação à experiência de Itaperuna, vinculada ao Ministério da Agricultura, segundo Rios, "ficou enquistada" devido ao desinteresse político do governo, pelo ministro João Cleofas de Oliveira. Portanto, há necessidade de mais investigações para concluir se a CNER derivou ou não da experiência de Itaperuna (ver entrevista no Anexo 1, em Barreiro, 1997). 
Em 1954, no VI Curso de Treinamento de Educadores de Base da CNER, Helena Antipoff ${ }^{6}$ (1954, p. 171) destacou a situação de abandono do meio rural por causa da omissão do poder público, criticou a política latifundiária de monocultura e o descaso das reivindicações dos trabalhadores rurais, vistas como "perigosas e facilmente inflamáveis", numa referência às interpretações dadas à pobreza como opção mais fácil ao comunismo.

As Missões Rurais de Educação - compostas por médico, engenheiro, agrônomo, enfermeira, professora e assistente social - foram o principal suporte de trabalho da CNER desenvolvido nos Centros Sociais de Comunidade. Em 1956, foram realizados acordos financeiros técnico-ideológicos entre a CNER e o Ponto IV $;^{7}$ a CNER e a Cooperativa Americana de Remessas para o Exterior dos EUA (CARE). ${ }^{8}$

A Campanha estabeleceu acordos com as arquidioceses do Maranhão e do Ceará, com o Serviço de Assistência Rural no Rio Grande do Norte, Secretarias da Educação dos Estados de Alagoas e do Rio de Janeiro, criando bases para os Centros Regionais de Treinamento de Professoras Rurais. Em 1952 foram formadas mais de 100 professoras, e até 1959 cerca de 1.500 concluíram cursos de treinamento (O treinamento..., 1959, p. 285).

Em 7 de dezembro de 1956, criou-se o Centro Regional de Educação de Base (CREB), em Colatina, no estado do Espírito Santo, o primeiro no Brasil destinado a formar a equipe de missões rurais, por meio de atividades de extensão educativa cultural, cursos de habilitação para professores rurais, núcleo de orientação para líderes rurais, núcleo cooperativo de treinamento agrícola e cursos para educadores de base (Boletim Mensal Informativo, 1960a). A Campanha explicitou que, em virtude da "urgência da extinção da fome, da nudez e do analfabetismo que lavra pelo mundo [...] não seria possível esperar-se pela ação morosa da escola primária e, muito menos, pelos favores, precários e duvidosos, dos chamados cursos de ensino supletivo" (Inauguração..., 1959, p. 107). Era necessário difundir “melhores métodos de cultura, notadamente, da conservação ou estabelecimentos da fertilidade do solo; uso de compostos e de adubos; processos mais racionais de irrigação e de drenagem, bem como o espírito de luta contra a erosão" (idem, ibidem).

6 Para melhor conhecimento acerca da relevância dos trabalhos dessa educadora russa na área da educação da rural, consultar Barreiro (2007).

7 O Ponto IV é uma agência americana interessada na expansão da ideologia da modernização e no modo de produção capitalista. Por meio da United States Operation Mission-Brazil, estabeleceu cooperação com as organizações municipais, estaduais e federais em prol do desenvolvimento dos níveis de padrão de vida das populações rurais (A CNER e o..., 1956, p. 84).

8 Por meio do convênio com a CARE, doavam-se ferramentas para agricultores, carpinteiros rurais, pertences para curativos e materiais de primeiros socorros destinados aos Centros Sociais de Comunidade, que receberam, por diversas vezes, visita de representantes sediados em Nova Iorque (A realidade e a..., 1956, p. 34). 
Ao assumir a urgência na melhoria da educação, com ações mais incisivas, afirmou:

Todos precisam conhecer como utilizar máquinas e ferramentas modernas, como selecionar sementes, como combater as doenças das plantas e os insetos nocivos; como arborizar, como afolhar, como reflorestar. A melhoria dos métodos de criação, a alimentação do gado no campo e nos estábulos; a utilização de plantas forrageiras e muitas outras noções de domínio da agricultura. Em uma economia industrial, o campo é vastíssimo para o lançamento e desenvolvimento da Educação de Base. (Inauguração..., 1959, p. 107)

Os técnicos do staff da Campanha eram enviados ao México para formação sólida sobre os princípios das missões culturais mexicanas, com bolsas de estudos ofertadas pelo Centro Regional de Educação Fundamental para a América Latina (CREFAL) e a UNESCO. Em 1958, seis técnicos da CNER foram treinados pelo Ponto IV em recursos audiovisuais, na Universidade de Bloomington, Indiana. No ano seguinte, mais sete técnicos receberam treinamentos de técnicos americanos no Rio de Janeiro (Cursos..., 1959, p. 203). Em 1956, a CNER estava presente em sete estados brasileiros, totalizando 45 centros sociais de comunidade, dos quais, 16 estavam localizados no Rio Grande do Norte. ${ }^{9}$ Depois de formados, os técnicos atuavam nos centros de treinamento para a formação de novos profissionais que desenvolveriam a educação rural voltada para a agricultura e cultura de modo geral.

\section{O ENSINO AGRÍCOLA NOS CENTROS DE TREINAMENTO DE PROFESSORES E DE AUXILIARES RURAIS}

A Campanha sempre explicitou dificuldades para encontrar professoras rurais bem formadas. Existiam professoras leigas, sem formação em escola normal ou com "curso pedagógico oficial". Denunciava, ainda, que "nossos prefeitos, quando se trata de nomear mestres municipais, não têm a menor preocupação no tocante ao preparo daqueles a quem os outros vão entregar os filhos para serem educados" (Telles, 1954, p. 62). Reconhecia que "depois de um curso de tão longa duração [4 a 5 anos], os egressos não se sujeitam a lecionar pelo salário diminuto ao qual o ensino municipal está pautado" e a lecionar no campo. Diante desse quadro, "Há necessidade, por conseguinte, de preparar moças radicadas na zona rural, em cursos de tempo reduzido, a fim de conseguir elementos [pessoas] que realmente façam o Curso com intenção de voltar ao campo e de valorizá-lo" (A criação e o..., 1961/1962, p. 13).

Com tais preocupações, o Centro de Treinamento de Professores e de Auxiliares Rurais oferecia cursos de treinamento às professoras que lecionavam e de

9 A Campanha atuou em áreas com conflitos pela posse da terra, até mesmo onde havia organização das Ligas Camponesas, movimento dos trabalhadores rurais. 
habilitação para lecionar em substituição ou em novas escolas, em regime de internato por dois meses, pautados nos princípios da educação de base. Esses cursos não deveriam ter longa duração, para evitar que as futuras professoras se desajustassem de suas comunidades.

Todavia é de reconhecer como imprescindível, a necessidade de um preparo mínimo essencial, de um domínio seguro das técnicas de ensino com vistas ao ambiente na formação do professor rural. Mas como a escola rural não o é apenas pelas suas condições externas de material ou de método de trabalhar, devem-se prever do educador rural além do preparo básico, certas qualidades de liderança e de amor ao meio rural, um aprofundado sentido social e humano de sua função, certa radicação a localidade e vocação pelo magistério, para que as funções essenciais que se espera da escola em benefício da comunidade sejam realmente cumpridas. (Telles, 1954, p. 63)

O conjunto documental da Campanha, composto por revistas e boletins que relatam o cotidiano dos trabalhos desenvolvidos nos diferentes centros de treinamentos, nem sempre expressa visões e posicionamentos unânimes acerca da educação e da própria política em execução, previsíveis no processo de criação e implementação das ações. A citação anterior exemplifica bem essa situação, na medida em que o autor reconhece que a educação não se restringe somente às condições materiais da escola e métodos de ensino, ao atribuir um valor social à educação.

Em abril de 1958, o decreto n. 1.367 criou a Escola Primária Rural de Aplicação de Métodos, em Colatina, no estado do Espírito Santo, para formar professoras e realizar complementação pedagógica de professoras/alunas e curso supletivo noturno para alfabetização de adultos (A criação e o..., 1961/1962, p. 13). Cabe destacar que a formação de professoras rurais pela CNER é anterior a 1958, em diferentes localidades do país, nos centros de treinamentos, e previa que "toda professora rural ao participar do curso deverá assumir, previamente, o compromisso de continuar a exercer o magistério em zona rural durante um ano no mínimo"(Do recrutamento..., 1961/1962, p. 40).

A ficha de inscrição para selecionar candidatas aos cursos, composta por 62 questões, tratava dos dados pessoais, das condições físicas e higiênicas da escola, do asseio pessoal dos alunos, se a escola tinha horta, filtro, jardim, fossa; se a candidata gostava da vida da roça e se os pais de alunos visitavam a escola. Indagava, ainda, os dotes e outros saberes da candidata, como: se sabia cozinhar, costurar, bordar e aplicar injeções; por último, por que desejava fazer o curso de treinamento para professoras (idem, p. 49-52). Em 1960, foram desenvolvidos 16 cursos para professoras, perfazendo o total de 472 participantes (Boletim Mensal Informativo, 1958b, p. 36).

As preocupações com a formação de professoras rurais estiveram presentes em todas as publicações da Campanha, assim como em seus 10 volumes de revistas, 
nos 50 Boletins, ${ }^{10}$ com 27 a 56 páginas cada um, bem como na participação do staff da Campanha em congressos, reuniões e encontros promovidos pela Igreja. Em 1961/1962, a Campanha editou um número especial da revista que tratou da "Estruturação de um Centro Regional Federal de Treinamento de Professores Rurais", com o histórico do Centro, a regulamentação, a previsão orçamentária e os programas dos cursos e disciplinas ministrados às professoras rurais, objeto de análise deste artigo.

O trabalho da Campanha, somado ao dos municípios e da liderança local, deveria exercer forças centrífugas e disseminar ensinamentos. Apesar das intenções explicitadas pelo programa de respeitar os valores locais, nos registros de atividades e diagnóstico das regiões, o olhar do "colonizador" pouco deixa escapar, conforme as descrições do engenheiro agrônomo Severino Pereira da Silva (1956, p. 130), ao afirmar que:

O rurícola, dado o seu isolamento, é um homem deformado. Ele vive esquecido, até de si mesmo, e num conformismo doentio se deixa arrastar, vida à-fora, cortando metade da existência pela ignorância que lhe aumenta a fome e mina-lhe o organismo com moléstias de carência. [...] A sua moral se fundamenta na promiscuidade familiar, que até lhe nega os sentimentos da pessoa humana. Sua vida espiritual é presa a crendices populares e sua escola é a mesmice, repetida de gerações a gerações.

Desse modo, os conteúdos desses cursos eram associados a outras "virtudes" que a professora deveria possuir ou desenvolver, favorecedora de mudanças, da adoção de novas práticas e formas de cultura entre os habitantes do campo. Os cursos para formação de professoras e auxiliares rurais eram complementados por unidades práticas temáticas, tais como: a criança, nossa horta, os animais e campanha das árvores. Além das disciplinas do ensino regular, outras compunham os programas dos cursos, como: formação moral e cívica, higiene e enfermagem, culinária, recreação e canto, formação, agricultura para o campo e agricultura para sala de aula (Unidades didáticas..., 1961/1962).

No curso de treinamento para professoras rurais, realizado em 1958, em Colatina, o programa de agricultura objetivava "[...] substituir as crenças e interpretações errôneas pelo conhecimento científico, empregando todos os recursos didáticos possíveis para a concretização dos objetivos: experimentação, demonstração" (Programa de agricultura, 1961/1962, p. 213), que consiste "[...] em induzir

10 Desses boletins, dez tratam de campanha das árvores, "para formar uma nova mentalidade entre crianças, jovens e adultos nas zonas rurais, tornando-os conscientes do integral valor da ÁRVORE na vida humana, da necessidade de preservar as florestas contra incêndios e o machado, de reflorestar sempre e de replantar toda vez que se necessite derrubar" (Boletim Mensal Informativo, 1960b, p. 36). Outros foram dedicados a temas de interesse do campo, como: "Férias, repouso semanal e seguro para os trabalhadores agrícolas", referente ao anteprojeto elaborado pela Comissão Nacional de Política Agrária, para assegurar garantias e vantagens aos agricultores, com o aval da CNER (Boletim Mensal Informativo, 1958b, p. 7, grifos do original). 
os elementos que assistem [à demonstração] a adquirirem o material, depois de verificarem a sua utilidade" (Xavier, 1956, p. 112).

Esperava-se que as crenças renovadas, aliadas às técnicas de experimentação e demonstração, associadas ao conhecimento científico, levassem à assimilação de novas técnicas e valores com menor resistência. Para Pedro Garcia (1977, p. 25), o efeito de demonstração consiste na interdependência entre um sujeito e outro no que concerne ao consumo. "Nesta interdependência, alguém que se depare com um padrão de vida superior tem o desejo de elevar o seu nível de consumo. A demonstração de um estilo de vida considerado superior suscitará, com 'efeito', o desejo de idênticas fruições”. José Arapiraca (1981, p. 23) também destaca que a “[...] escola permite no seu interior e no curso da sua pedagogia que até mesmo as resistências culturais às inovações sejam racionalizadas ou não, bastando para tanto que haja uma intencionalidade por parte de quem tenha competência na objetivação de seus fins".

Esse potencial atribuído à educação esteve presente nos objetivos do IV Curso de Treinamento para Professoras Rurais, em 1958, em Colatina. A unidade nossa horta propôs-se a: 1) desenvolver técnicas de trabalho em grupo; 2) considerar a utilidade dos vegetais e interesse pelo cultivo de hortaliças; 3 ) fortalecer as atitudes de exatidão, ordem, economia, solidariedade, justiça, socialização, disciplina; 4) desenvolver a liderança; 5) criar hábitos de pesquisa (Unidades didáticas..., 1961/1962, p. 99). Cada curso de treinamento era composto por diferentes disciplinas articuladas entre si, com 9 a 18 horas/aula, cada uma delas, que muitas vezes se revertiam em apresentações práticas das alunas no auditório do Centro de Treinamento como parte da disciplina recreação: brinquedos, jogos e fantoches, com 12 horas, e eram assistidas por autoridades da Campanha.

Em agricultura (campo) tratava-se de questões práticas para construção da horta, preparo dos canteiros, semeadura, plantio de mudas, bem como o uso de "ferramentas, adubos, inseticidas e mudas, enquanto para agricultura (sala de aula), [...] discutia-se a realização da excursão à horta, aproveitando todos os aspectos para a aprendizagem em alfabetização e memorização com técnica" (idem, p. 101). A formação moral e de novos valores esteve a cargo da disciplina formação moral e cívica, com conteúdos relacionados a "Amor à ordem e à pontualidade. Amor ao trabalho (em qualquer atividade). Respeito à propriedade. Desenvolvimento de hábitos de economia bem entendida. Obediência. Bom humor e alegria"(idem, p. 102).

Desse modo, a associação entre educação rural, ensino agrícola, educação higiênica e reforma agrária foi mais bem explicitada quando, em 1959, a CNER traçou um panorama do meio rural e descreveu a presença de populações rarefeitas, distantes, isoladas, com problemas de "[...] a) agricultura extensiva; b) ignorância (analfabetismo, falta de hábitos higiênicos, de técnicas racionais de trabalho e de produção, etc.); c) problemas racionais ambientais de seca, endemias, etc., determinando o nomadismo" (Rápida..., 1959, p. 277). Mais uma vez reiterou:

[...] faz-se necessária a REFORMA AGRÁRIA brasileira, precedida, porém da preparação do homem para essa reforma, incutindo-lhe o espírito de socia- 
bilidade e da ação em grupos, educando e orientando aqueles através destes e predispondo-os à aprendizagem dos conhecimentos fundamentais para uma vida melhor [...] sem os atritos peculiares às ideologias extremistas. (Rápida..., 1959 , p. 277, destaques do original)

Valendo-se de seu referencial teórico e das parcerias com a Igreja católica, a Campanha manteve posturas ambíguas, de modo que ora se posicionou a favor do homem do campo, ora dos latifundiários. D. Eugênio Salles trabalhou na promoção da reforma agrária com vistas à "recuperação humana e cristã do trabalhador rural" (Camargo, 1984, p. 146), atuou na organização de "sindicatos cristãos", em Natal (Andrade, 1986, p. 72), e trabalhou como executor de projetos na CNER, desde 1952. Em 1959, todos os cargos de executores de projetos da Campanha, do Norte e Nordeste, pertenciam a bispos e padres, o que a levou a uma maior atuação nas regiões com movimentos sociais, especialmente as Ligas Camponesas. Em pesquisa anterior, Barreiro (2010, p. 87-101) realizou levantamento exaustivo acerca da atuação da Campanha em municípios de diferentes regiões do país com movimentos sociais no campo.

Nessa complexidade social e educacional, a função social da escola atende a vários objetivos, ao ofertar conhecimentos favorecedores da adoção de novos valores e cultura. Mesmo com o propósito de criar "hábitos de pesquisa, solidariedade, justiça", reconhecidos como fundamentais para a educação e para a cidadania, estes podem diluir-se quando associados ao trabalho pedagógico utilitarista para "fortalecer atitudes de exatidão, ordem, disciplina e liderança” (Unidades didáticas..., 1961/1962, p. 99). Porém, é difícil não reconhecer a descrição do geógrafo Luiz Rogério de Souza, executor da Campanha. Sem mencionar a localidade, ele afirma:

A escolinha da roça, animada e ajudada pela professora (que sempre viveu abandonada a si mesmo), cria um novo elan [sic] e retira da equipe toda a colaboração possível; fazem-se palestras e demonstrações dentro do currículo ou nos intervalos; organizam-se clubes agrícolas e pelotões de saúde, cultiva-se a horta, faz-se experiência da sopa escolar; começam-se pequenos projetos de artes manuais; faz-se boa recreação, em rodas, canções, dramatizações diversas, teatrinho de fantoches (preparados os bonecos pelas mesmas crianças); os cursinhos de costura e bordados absorvem o interesse e o entusiasmo das garotas - a escola começa a viver e atrair a criançada. (Souza, 1954, p. 53)

O relato explicita contradições da Campanha ao abarcar o espectro amplo de saberes e cultura no combate à pobreza e à precariedade das populações rurais, de fato abandonadas pelo Estado, e também relata dificuldades para fixar-se nas grandes regiões latifundiárias. Isso pode ser indicativo de que "a aplicação da metodologia de desenvolvimentos e organização de comunidades não era suficiente para provocar o desenvolvimento, e que este dependia de outros fatores que não o educativo"(Fonseca, 1985, p. 57), como uma política pública de Estado incisiva e não a critério de governos e municípios. Esse fato certamente explica a situação de exclusão da população rural concentrada em determinados estados do Brasil, até mesmo onde a CNER atuou fortemente. 
A falta de higiene e a saúde frágil da população rural eram vistas como decorrentes de problemas agravados pelo "pouco uso dos talheres e a ausência de higiene das mãos [, que] completam o quadro sombrio para a saúde que representa o rurícola à mesa de refeições, ao mesmo tempo em que ingere alimentos, leva também ao seu corpo os elementos nocivos à saúde" (Aspectos..., 1955, p. 77).

Nesse sentido, o $1^{\circ}$ Curso de Habilitação para Professores Rurais, realizado em 1958, discutiu os tabus alimentares como a combinação de "feijão, angu de milho e couve, [...] como servir a refeição: arranjo da mesa e serviço" (Unidades didáticas..., 1961/1962, p. 102). Jurandir Costa Freire (1979, p. 88), ao analisar a decomposição dos aspectos culturais da família colonial e os desdobramentos dessas alterações em relação às refeições, considera que

[...] o ritual da alimentação, a reunião da família em torno da mesa, atende a necessidades outras que não as de pura nutrição biológica [...]. É o momento de transmitir o modo de vida, o modo contido, disciplinado, higiênico e polido, funciona como norma do bem conduzir-se na casa e na vida.

De fato, os objetivos dos cursos iam além da boa alimentação; propunham-se a desenvolver condutas normativas pelo programa da disciplina educação moral e cívica, como ocorreu em um dos cursos de habilitação para professoras: "desenvolver conduta no lar, nas ruas, na escola, na igreja, nas casas de diversões, à mesa” (Programa de educação..., 1961/1962, p. 207). Esse conteúdo e o da unidade educação moral e religiosa destacaram-se pelo caráter normatizador e ideológico ao discutir "amor ao trabalho, respeito à propriedade, obediência, bom humor e alegria", entre outros temas (idem, p. 206), bem como questões acerca da "defesa das terras e as invasões" (idem, p. 205), pelo programa de história e educação cívica.

Portanto, as novas aprendizagens não se restringiam à incorporação de novos conhecimentos vinculados à realidade do campo e à cultura mais geral, mas de readequação de condutas e modos de vida que atendessem ao desenvolvimento econômico e às necessidades da sociedade brasileira, a partir de 1950, decorrentes da industrialização e mecanização agrária. Desse modo, a preocupação em sanear o meio ambiente do campo pareceu, antes de tudo, estar mais associada à intenção de regenerar e disciplinar essa população segundo valores mais urbanos. Margareth Rago (1985, p. 174), ao estudar o movimento histórico de formação do mercado livre do trabalho no Brasil, no período de 1890-1930, afirmou que a remodelação da casa imunda "induz uma estratégia disciplinar na qual desinfecção e submissão são assimilados simbolicamente: o sonho de tornar o pobre inodoro sugere a possibilidade de construir o trabalhador comportado e produtivo".

No programa do VI Curso de Treinamento para Professoras, no módulo a criança, ao lado dos ensinamentos preventivos de doenças infantis, a questão da moral objetivou "levar as alunas (professoras) a respeitar em si próprias e nos outros os preceitos da moral social mais elevada e as necessidades do espírito" (Curso de treinamento..., 1961/1962, p. 120). Observa-se a preocupação de introduzir conceitos mais apropriados ao processo de racionalização de trabalho na agricultura, 
não somente na sala de aula, mas também no lazer orientado desenvolvido pelas professoras e pelo técnico em recreação nas escolas rurais, para "promover a organização das horas sociais e o uso da recreação como aproveitamento das horas de lazer" (Programa de recreação, 1961/1962b, p. 229) de modo que

A professora, ao planejar suas aulas, terá o cuidado de planejar também o recreio. O recreio será dirigido sempre que possível. Inicialmente, até que se desenvolva a liderança dos grupos, terá direção cuidadosa da Professora. O recreio livre, desordenado, é prejudicial, deseducativo. Além de divertir as crianças, o recreio dirigido desenvolve grande número de qualidades, como sejam: espírito de ordem, de obediência, altruísmo. (Programa de recreação, 1961/1962a, p. 82)

O lazer formativo também foi usado como meio de pôr fim à monotonia do meio rural, para "proporcionar à população rural alegria de viver"; o lazer habitual, como festas, ir à igreja, à casa de vizinhos, era considerado inadequado e gerador de doenças em virtude da "falta de higiene mental, de bom relacionamento e de recreação sadia, que acabam por desencadear a enfermidade, mesmo nos elementos de melhores condições sociais" (Aspectos..., 1955, p. 87).

Recursos didáticos como teatro de fantoche e cinema educativo foram amplamente usados pelo impacto que as imagens podem provocar como regeneradoras de costumes, em razão do poder simbólico e cultural expresso nas histórias, para a formação de nova mentalidade e comportamentos. O Jeca Tatu, de autoria de Monteiro Lobato, era valorizado como alguém que saiu da condição de doente e pobre para se tornar fazendeiro. A CNER orientava o setor médico-sanitário e as professoras para atuarem por meio de palestras, filmes educativos, histórias ilustradas, pois "Estudos cuidadosos provam que os filmes dramáticos exercem profunda influência nos hábitos e nas atitudes sociais das crianças e dos adultos" (Haidar, 1954, p. 116).

A preparação de professoras para o magistério na zona rural alinhou-se à tendência da época de "criação de 'escolas normais rurais', cuja denominação expressava não apenas a localização da escola em zonas agrícolas e pastoris, mas sobretudo o objetivo de transmitir conhecimentos de agronomia e higiene rural orientadas por uma consciência agrícola" (Tanuri, 2000, p. 75). Nesse sentido, a formação rural e agrícola destinada às professoras foi fortemente orientada pela "educação dos costumes", para a reformulação das casas, a melhoria da saúde, da higiene e do lazer, com alertas para preservação da propriedade privada e preparação para uma reforma agrária "civilizada".

Ao longo de toda a documentação produzida pela CNER, como os 10 volumes das revistas (compostas por artigos teóricos e descrição dos trabalhos do programa) e os mais de 40 exemplares do Boletim Mensal Informativo, que descreve minuciosamente o cotidiano dos trabalhos, fica evidente o quanto as políticas educativas estão sujeitas à interpretação e recriação dos diferentes atores (tanto da parte daqueles que a desenvolvem como daqueles que a recebem), sofrendo interpretações e recriações em relação à proposição original da política.

Há que se considerar ainda as representações sociais acerca da política e do meio a qual se destina, cujas formas de expressão são vivenciadas no contexto da prática, 
possibilitando diferentes interpretações da realidade acompanhadas, igualmente, por diferentes ações na prática. As reflexões de Janete Azevedo (2004,p. XIV) contribuem para a compreensão desse processo ao afirmar que "as políticas públicas, como qualquer ação humana, são definidas, implementadas, reformuladas ou desativadas com base na memória da sociedade ou do Estado em curso". Desse modo, prossegue a autora,

[...] as políticas públicas são ações que guardam intrínseca conexão com o universo cultural e simbólico ou, melhor dizendo, com o sistema de significações que é próprio de uma determinada realidade social. As representações sociais predominantes fornecem os valores, normas e símbolos que estruturam as relações sociais e, como tal, fazem-se presentes no sistema de dominação, atribuindo significados à definição social da realidade que vai orientar os processos de decisão, formulação e implementação das políticas. (idem, p. XIV-XV)

Logo, cabe indagar como se caracterizava a sociedade e o Estado, em curso, no período da Campanha (1952-1963)? O espaço deste texto não permite uma resposta rigorosa, mas é possível considerar o quanto as políticas devem ser interpretadas no contexto que as ensejou. A década de 1950, em particular a segunda metade, foi marcada pelo avanço da industrialização, com desdobramentos na agricultura pela ampliação da mecanização e uso de insumos. Este desenvolvimento econômico do país contou com vigoroso investimento público direto do Estado, do capital internacional e privado nacional. O segundo governo de Vargas (1951-1954) priorizou a montagem de infraestrutura para o desenvolvimento econômico, para a promoção da industrialização, buscou aliança com os EUA por meio de empréstimos públicos e colaboração técnica. No governo de Kubitschek (1956-1961), a meta foi desenvolver o "50 anos em 5".

Portanto, é nesse contexto que a Campanha existiu e, ao mesmo tempo em que se colocava como imperativo desenvolver as populações rurais e conter o êxodo rural, também se colocava em xeque o potencial da escola rural como formadora do homem do campo numa perspectiva integral de educação e cultura, por meio da educação informal, na qual

[...] a escola passa a ser apenas um dos fatores da educação, podendo proporcionar ao educando instrumentos para a aprendizagem, recursos mentais que ampliem a capacidade e a compreensão dos indivíduos para melhor utilização de outras oportunidades educativas. (Souza, 1954, p. 55)

Desse modo, a Campanha enfatizava que os cursos de treinamento para professores rurais

[...] incluem em seus currículos as mais variadas atividades desenvolvidas em caráter dinâmico e global, entrosadas e aplicadas à realidade dos problemas da vida rural, como, agrícolas, educação para o lar, para a comunidade, culinária, trabalhos manuais, costura, noções de enfermagem, puericultura [...]. (Boletim Mensal Informativo, 1958a, p. 19) 
Para ilustrar essa afirmação, em Colatina, no Centro Regional de Educação de Base, a oferta da merenda escolar aos alunos era preparada pelas professoras estagiárias, sendo esta uma de suas atribuições.

Logo, ainda que sob o olhar do "colonizador", em diferentes momentos essa formação docente ocorreu em meio a outras atividades educacionais e civis promovidas pela Campanha, como discussões entre os habitantes do campo para eleições de diretorias dos Centros de Comunidade, como incentivo ao exercício de direitos civis. Em Sapiranga, no Rio Grande do Sul, ocorreu a "campanha do registro civil", com registro de 120 pessoas, 16 casamentos no civil e a isenção de taxas para os encaminhados pela missão (Boletim Mensal Informativo, 1959, p. 10). Construção da fossa higiênica, preservação do meio ambiente, vacinação contra o tétano, prevenção do tracoma, da sífilis, da tuberculose, uso da água filtrada para combater a verminose e a mortalidade infantil são exemplos de outras atividades.

A exposição e análise realizada até o momento evidenciou, portanto, contradições na prática da Campanha, que podem ser interpretadas como decorrentes da atribuição de significados e de interpretação daquela realidade social, que no campo era fortemente marcada pela pobreza e pelo analfabetismo, diante de um pretenso desenvolvimento econômico que se anunciava com o aprofundamento de mudanças na nossa sociedade, de marcadamente agrária para industrial. Tais contradições foram relatadas na documentação pelos técnicos e missioneiros como "boatos" que ocorriam entre a Campanha e os habitantes rurais ao "boicotarem" os trabalhos, sendo que em outros momentos aderiam às atividades formativas de direitos civis. Ainda foram relatadas tensões entre a Campanha e os latifundiários, que a viam como uma ameaça ao seu poderio, conforme será tratado a seguir.

\section{CONTRADIÇÕES E LIMITES NA PRÁTICA EDUCATIVA DA CAMPANHA}

Como elemento fundamental da cidadania política está a valorização da educação política, sobretudo na perspectiva da participação popular, na qual os próprios interessados se transformam em novos sujeitos políticos (Benevides, 1994, p. 5-6). O exercício da cidadania supõe o cultivo de algumas condições sociais e políticas para o desenvolvimento da democracia, entre elas a mudança da consciência popular, que, em vez de mera consumidora, passa a se ver como agente e executora capaz de desfrutar de suas próprias decisões (Chauí, 1981, p. 86-95).

Criada para desenvolver a cidadania no meio rural, por meio da educação de base, a Campanha privilegiou ações pedagógicas mediante a educação informal para além da escola rural. Ações essas que objetivavam modificar a realidade de pobreza e precariedade do meio rural ao mesmo tempo em que promoveria o desenvolvimento econômico e a autonomia do homem do campo. As dificuldades no trato com as questões culturais do homem do campo eram reconhecidas por técnicos e membros formadores das equipes da CNER, como Helena Antipoff, que afirmou que as palavras dos educadores poderiam constituir-se em forças sociais, desde que relacionadas e incorporadas à realidade social da população, para diminuir possíveis resistências aos novos ensinamentos educativos: 
A inovação de qualquer medida, perfeitamente aceitável e de inteiro bom senso, pode acarretar, pelos efeitos não previstos, consequências das mais graves e negativas [...] os obstáculos, bem sabeis, podem provir da ignorância das próprias massas rurais e do apego irracional às formas tradicionais de vida, de trabalho, de maneiras de pensar impermeáveis à experiência, como em toda sociedade de civilização primitiva. (Antipoff, 1954, p. 171-172)

Para exemplificar, Antipoff (idem, p. 173) relatou um episódio ocorrido em um dos Centros de Treinamento para Professores Rurais, em Minas Gerais, beneficiado com um motor gerador de luz elétrica mais potente, conseguido por meio de abaixo-assinado entre os moradores, estimulado pela Campanha, que gerou um novo fato decorrente da melhoria: "Antes, [...] o povoado mergulhava no silêncio da noite e seus habitantes tranquilamente restauravam as energias gastas durante o dia que começava cedo". Com a expansão da luz elétrica, a iluminação estendeu-se pela noite, aumentou as horas de vigília, de lazer, e os habitantes criaram novos hábitos incompatíveis com os objetivos do programa educativo. Aumentou o consumo de bebidas alcoólicas, o número de botequins, a frequência masculina, “à qual tendem se juntar elementos femeninos mais levianos, [...] com irradiações das canções carnavalescas, histórias tolas e dramas cheios de histerismo difundidos pelas estações das metrópoles vieram interferir com as modinhas, cantigas populares e serenatas tradicionais ali" (idem, ibidem). A descrição explicitou contradições, dilemas e conflitos vividos pela educadora entre culturas diferentes, na medida em que os beneficiados passaram a usar o novo bem, mas diferentemente dos objetivos definidos. Brandão (1986, p. 76) foi assertivo ao tratar das complexidades existentes nas relações educativas, nas quais muitas vezes as classes subalternas deixam-se invadir por não terem formas de controle, mas depois de invadidas desenvolvem mil artimanhas como instrumentos de resistência.

Artimanhas que apareceram na descrição da pasta de campo de uma missão rural de Jequié-Ipiaú, no município de Tesourinha-BA, quando, em virtude de "dificuldades surgidas pelas barreiras culturais ou rotinas de tradição” (Como trabalha..., 1955, p. 99), membros da missão contataram uma moradora da localidade e provável líder para agendar uma reunião no bairro. No relato que a Campanha fez no dia 23 de janeiro de 1955, foi afirmado que ao chegarem para a reunião, agendada há uma semana, não havia ninguém. A líder informou que "a Missão havia modificado o programa: em vez de reunião, visto o povo ser muito ignorante, haveria uma sessão cinematográfica, à noite...". Diante da explicação, concluíram os missioneiros: "Percebemos que surgira um engano ou haveria, talvez, elementos mal intencionados, que estariam agindo no sentido da dispersão do povo" (idem, p. 101). É presumível que situações dessa natureza eram recorrentes, na medida em que em outro momento a Campanha afirmou: "Sugerimos que, para vencer a resistência - embora essa seja velada - que a Missão atacasse o trabalho mais intensamente nas regiões mais densas e mais pobres [...]" (Levantamento..., 1954, p. 167). Merece destaque o fato de a líder ter usado as mesmas qualificações usadas pela Campanha, como população ignorante e atrasada 
culturalmente. Ou seja, a apropriação da terminologia serviu, nesse caso, como arma para se contrapor aos trabalhos do programa.

Ainda no estado da Bahia, no distrito de Varzinha, a Campanha relatou que haviam criado clubes de mãe, de moças, infantil e de homens; os trabalhos obedeciam à rotina e o interesse dos grupos aumentava. No entanto, a equipe da missão rural ficou impossibilitada por dois meses de comparecer à localidade por causa das chuvas e pelo fato de uma caminhonete estar com defeito mecânico. Ao retornarem, perceberam que

[...] indivíduos invejosos (neste caso, um charlatão) espalhou os boatos de que a Missão Rural era comunista, que os missioneiros tinham mau cheiro de chifre queimado, que eram hereges, etc. Muitos sócios procuraram afastar tais boatos, mas eles continuam a circular. (Um relatório..., 1956, p. 43)

A Campanha, em alguns momentos, era vista com restrições pelos latifundiários, temerosos de perderem poder:

Esse é um dos principais problemas, e uma das razões da desconfiança e restrição com que a Missão é vista por alguns chefes políticos e vereadores. Escondem o receio da perda de prestígio e de uma hegemonia injustificada, demonstrando pessimismo em relação ao sucesso do trabalho da Missão e descrevendo o roceiro como um preguiçoso, obstinado ou ignorante, incapaz de civilizar-se. (Pesquisa..., 1955, p. 91)

A Campanha tinha dimensão do poder e alcance das ligações personalistas e clientelistas dos coronéis que dificultavam o estabelecimento de relações democráticas e de exercício da cidadania do homem do campo como eleitor, desvinculado de favores.

No intuito de se contrapor a essa conjuntura de dominação, a Campanha procurou desenvolver um trabalho educativo articulado ao processo da cidadania civil e política, tratando do valor do voto e da importância de se escolher bem os representantes. Incentivou os habitantes rurais a realizarem reuniões para levantar seus problemas e proporem formas de encaminhamentos, além de proporcionar situações para que crianças e adultos fossem adquirindo o hábito de eleger seus agentes políticos. "Quisemos assim atingir a consciência política, por assim dizer, nula no meio" (Como trabalha..., 1955, p. 104).

Desse modo, a cidadania civil e política para o meio rural foi trabalhada também nos cursos de treinamento de professores. O programa de bistória e educação cívica discutia a educação política entre os professores, extensiva aos habitantes rurais. Previam-se conteúdos voltados para noções básicas da constituição política do Estado, da necessidade de governo, dos símbolos nacionais e dos três poderes, conhecimentos que contribuem para a formação dos preceitos da cidadania. Discutia-se, ainda, a organização política e administrativa do Brasil, o dever do voto, a necessidade de leis e de governo, o significado da Pátria, a Bandeira e o Hino Nacional (Programa de história..., 1961/1962, p. 74). 
Nesse sentido, foi de grande significado o encaminhamento de uma Missão Rural de Educação da Campanha em uma comunidade que teve a escola fechada por causa da remoção da professora pelo prefeito. Após várias reuniões no bairro, promovidas pela missão, decidiu-se que uma delegação de crianças iria falar com o prefeito. Para tanto

[...] tratou-se do critério de eleição, a responsabilidade do voto, da necessidade de escolher os mais capazes para a incumbência; e por fim, dez garotos foram eleitos, em voto secreto, para essa missão. A viatura da equipe encarregou-se de transportar à cidade os delegados, que foram deixados na residência do Prefeito. [...] Quinze dias depois dessa entrevista, estava nomeada uma nova professora e a escola municipal estava funcionando. A garotada tem consciência de que aquela escola é deles, pois foram eles que a conseguiram. (Souza, 1956, p. 90-91).

A Campanha sempre valorizou a realização de reuniões como espaço formativo, com discussões favorecedoras da construção da consciência política do homem do campo, da capacidade de julgar, decidir e escolher seus representantes, procurando desvincular-se do sistema coronelista. Ao longo de seus trabalhos, procurou ampliar o espaço político para a emergência da democracia participativa, ao mesmo tempo em que coexistiram visões e práticas que obstaculizavam avanços democráticos, por exemplo, quando a resolução dos atritos era encaminhada de modo particularizado, em que os habitantes deveriam falar com os proprietários de terra, ou ainda o incentivo a condutas morais. Enfim, tudo isso sintetiza e exprime as contradições, tensões e limites da prática educativa.

\section{CONCLUSÕES}

Ao olhar para a CNER de modo macro e de forma mais vertical para a problemática tratada neste artigo, é possível levantar pontos conclusivos de duas ordens: a forma e o alcance de atuação da Campanha, e o ensino agrícola na formação de professoras e auxiliares rurais.

A CNER constitui-se com base em estrutura complexa, organizada por muitos centros sociais e centros de treinamento para formação de seu staff técnico, com a finalidade de formar professoras rurais e auxiliares rurais, líderes rurais, técnicos agrícolas, técnicos sanitários, médicos rurais e outros profissionais, em regime de internato, que desenvolveriam suas ações com diferentes estratégias e localidades.

Constitui-se na primeira iniciativa de ação sistematizada para o campo, de caráter nacional, que rompeu com práticas e experiências descontínuas anteriores a ela. As descrições do meio rural e de seus habitantes a levaram a privilegiar ações pedagógicas intra e extraescolar para modificar a precariedade desse meio, promover o desenvolvimento econômico, a organização coletiva e a autonomia do homem no campo, com inserção diferenciada nas regiões e estados brasileiros. Nesse sentido, seu trabalho permitiu o afloramento de contradições que redundaram em brechas para a emergência de processos participativos dos habitantes rurais, ainda que 
pontuais, mesmo que o ensino agrícola tenha cumprido outras finalidades, para além daquelas requeridas por esse campo de conhecimento, como a de estimular a aquisição de valores morais e regrados.

A falta de professoras rurais formadas e os baixos salários denunciados pela CNER desnudaram, ainda mais, a permanência de problemas e descasos dos governantes ainda nos tempos atuais, ao darem continuidade à desvalorização da profissão docente. Mesmo com um sistema educacional atual mais inclusivo, a estas alturas não deveria possuir similaridades com problemas quase centenários, em particular para o campo.

É possível afirmar que nesse processo educativo houve mudanças na consciência dos educandos que agiram não mais como consumidores, mas como agentes que desfrutam de suas próprias decisões. Essas situações não podem ser generalizadas em todas as ações da Campanha, pois diversos fatores culturais históricos constroem processos diferenciados de representações que interferem nos processos de implementação, aceitação e rejeição no desenvolvimento de uma determinada política.

Enfim, mesmo com as restrições que se possam fazer à CNER, acerca das contradições que marcaram sua existência e atuação, certamente ela foi relevante naquelas circunstâncias históricas, não fosse o clientelismo e a descontinuidade das políticas públicas no país. $\mathrm{O}$ desenvolvimento da cidadania e o direito à educação continuam na ordem do dia, evidenciando que as políticas públicas, além de ter continuidade, devem dialogar entre si.

\section{REFERÊNCIAS}

A CRIAÇão e o desenvolvimento do centro regional de educação de base. Revista da Campanha Nacional de Educação Rural, Rio de Janeiro: Ministério da Educação e Cultura,v. 10, p. 13-23, 1961/1962.

A CNER e o Ponto IV. Revista da Campanba Nacional de Educação Rural, Rio de Janeiro: Ministério da Educação e Cultura, v. 4, p. 84-86, 2º sem. 1956.

A REALidAde e a grandeza do trabalho em equipe entre entidades públicas e particulares no Brasil. Revista da Campanba Nacional de Educação Rural, Rio de Janeiro: Ministério da Educação e Cultura, v. 3, p. 31-34, 10 sem. 1956.

Aguiar, Antonio Geraldo de. Serviço social e filosofia: das origens a Araxá. 4. ed. São Paulo: Cortez, 1985.

Ammann, Safira Bezerra. Ideologia do desenvolvimento de comunidade no Brasil. 6. ed. São Paulo: Cortez, 1987.

Andrade, Manoel de. Lutas camponesas no Nordeste. São Paulo: Ática, 1986.

Antipoff, Helena. Aula inaugural do VI Curso de Treinamento de Educadores de Base da CNER. Revista da Campanha Nacional de Educaşão Rural, Rio de Janeiro: Ministério da Educação e Cultura, v. 1, p. 168-173, 1954. 
Arapiraca, José. Escola de produção comunitária: uma proposta de desenvolvimento integrado tomando a escola como centro. In: Seminário sobre Meio RuRal e Educação, 1., 1981, Rio de Janeiro. Anais... Rio de Janeiro: IESAE; Fundação Getúlio Vargas, 1981.

Aspectos médicos sanitários. Revista da Campanha Nacional de Educação Rural, Rio de Janeiro: Ministério da Educação e Cultura, v. 2, p. 69-91,1955.

Azevedo, Janete Maria Lins de. A educação como politica pública. 3. ed. Campinas: Autores Associados, 2004.

Barreiro, Iraíde Marques de Freitas. Cidadania e educação rural no Brasil: um estudo sobre a Campanha Nacional de Educação Rural - 1952-1963. Tese (Doutorado) - Faculdade de São Paulo, Universidade de São Paulo, São Paulo, 1997.

. Helena Antipoff - a educadora ruralista: a construção de um acervo pessoal e sua relevância para a educação na atualidade. Patrimônio e Memória, Assis: CEDAP; Faculdade de Ciências e Letras, v. 3, n. 1, p. 130-145, 2007. Disponível em: <http://www.cedap.assis. unesp.br/patrimonio_e_memoria/patrimonio_e_memoria_v3.n1/iraide_marques_de_freitas. pdf $>$. Acesso em: 10 out. 2012.

. Política de educação no campo: para além da alfabetização (1952-1963). São Paulo: Editora UNESP, 2010. Disponível em: <http://books.scielo.org/id/q7zxz>. Acesso em: 10 out. 2012.

Benevides, Maria Victória. Cidadania e democracia. Revista Lua Nova, São Paulo, CEDEC, v. 33, p. 5-16, 1994.

Boletim Mensal Informativo n. 6. Rio de Janeiro: Ministério da Educação e Cultura/ Campanha Nacional de Educação Rural, 1958a, p. 12-20.

Boletim Mensal Informativo n. 10. Rio de Janeiro: Ministério da Educação e Cultura/ Campanha Nacional de Educação Rural, 1958b, p. 12-36.

Boletim Mensal Informativo n. 23. Rio de Janeiro: Campanha Nacional de Educação Rural; Ministério da Educação e Cultura, 1959, p. 4-12.

Boletim Mensal Informativo n. 28. Rio de Janeiro: Campanha Nacional de Educação Rural; Ministério da Educação e Cultura, 1960a, p. 4-5.

Boletim Mensal Informativo n. 33. Rio de Janeiro: Campanha Nacional de Educação Rural; Ministério da Educação e Cultura, 1960b, p. 20-36.

Bonilla Segura, Guillermo. As missões culturais no México. Revista Brasileira de Estudos Pedagógicos, Rio de Janeiro: INEP, v. 14, n. 38, p. 49-58, jan./abr. 1950.

BRAndÃo, Carlos Rodrigues. Da educação fundamental ao fundamental da educação. Cadernos do CEDES, São Paulo: Cortez Editora; Autores Associados, n. 1, ano I, p. 5-35, 1980.

. A educação como cultura. São Paulo: Brasiliense, 1986.

Calazans, Maria Julieta Costa. Estudo retrospectivo da educação rural no Brasil. Rio de Janeiro: Fundação Getúlio Vargas, 1979.

CAmARgo, Aspásia Alcântara. A questão agrária: crise de poder e reformas de base.In: Boris, Fausto (Coord.). História geral da civilização brasileira. São Paulo: Difel, 1984. p. 121-224.

Chauí, Marilena. Cultura e democracia: o discurso competente e outras falas. 2. ed. São Paulo: Moderna, 1981. 
Como trabalha uma equipe de Missão Rural da CNER. Revista da Campanba Nacional de Educação Rural, Rio de Janeiro: Ministério da Educação e Cultura, v. 2, p. 98-119, 1955.

Curso de treinamento de professoras-1958. Revista da Campanba Nacional de Educaşão Rural, Rio de Janeiro: Ministério da Educação e Cultura, v. 10, p. 120-133, 1961/1962.

Cursos audiosvisuais realizados junto a professores rurais. Revista da Campanha Nacional de Educação Rural, Rio de Janeiro: Ministério da Educação e Cultura,v. 8, p. 203-207, 1959. Do recrutamento e seleção. Revista da Campanha Nacional de Educação Rural, Rio de Janeiro: Ministério da Educação e Cultura, v. 10, p. 40-45, 1961/1962.

Fonseca, Maria Teresa Lousa da. A extensão rural no Brasil: um projeto educativo para o capital. São Paulo: Loyola, 1985.

Freire, Jurandir Costa. Ordem médica e norma familiar. Rio de Janeiro: Edições Graal, 1979. Garcia,Pedro Benjamim. Educação: modernização ou dependência? Rio de Janeiro: Livraria Francisco Alves, 1977.

Haidar, Chicralla. Filme e educação. Revista da Campanha Nacional de Educaşão Rural, Rio de Janeiro: Ministério da Educação e Cultura, v. 1, p. 113-116, 1954.

Inauguração do centro regional de educação de base. Revista da Campanha Nacional de Educação Rural, Rio de Janeiro, Ministério da Educação e Cultura, v. 8, p. 107-109, 1959.

Levantamento socioeconômico por uma equipe de Missão Rural da CNER. Revista da Campanba Nacional de Educação Rural, Rio de Janeiro: Ministério da Educação e Cultura, v. 1,p. 133-167, 1954.

Lima, Miguel Alves de. Reconhecimento geográfico para instalação de uma missão rural no estado de Alagoas. Revista da Campanha Nacional de Educação Rural, Rio de Janeiro: Ministério da Educação e Cultura, v. 1, p. 117-132, 1954.

MaIA, Eni Maria. Educação rural no Brasil: o que mudou em 60 anos? Revista ANDE, São Paulo: Associação Nacional de Educação, v. 3, p. 3-15, 1982.

O ponto IV na América. Jornal do Brasil, Rio de Janeiro, 19 set. 1952.p. 5.

O treinamento do professorado rural e a organização da comunidade. Revista da Campanba Nacional de Educação Rural, Rio de Janeiro: Ministério da Educação e Cultura, v. 8, p. 284-290, 1959.

PaIva, Vanilda Pereira. Educação popular e educaşão de adultos. 4. ed. São Paulo: Editora Loyola, 1987.

Pesquisa informal do município de São João Del Rei realizada pela equipe da Missão Rural aí instalada. Revista da Campanba Nacional de Educação Rural, Rio de Janeiro: Ministério da Educação e Cultura, v. 2, p. 57-91, 1955.

Programa de agricultura. Revista da Campanha Nacional de Educação Rural, Rio de Janeiro: Ministério da Educação e Cultura, v. 10, p. 212-216, 1961/1962.

Programa de educação moral, social, cívica e religiosa. Revista da Campanha Nacional de Educação Rural, Rio de Janeiro: Ministério da Educação e Cultura,v. 10,p. 206-207,1961/1962. Programa de história e educação cívica. Revista da Campanba Nacional de Educação Rural, Rio de Janeiro: Ministério da Educação e Cultura, v. 10, p. 73-79, 1961/1962. 
Programa de recreação - CTPR. Revista da Campanba Nacional de Educaşão Rural, Rio de Janeiro: Ministério da Educação e Cultura, v. 10, p. 82-83,1961/1962a.

Programa de recreação. Revista da Campanha Nacional de Educação Rural, Rio de Janeiro: Ministério da Educação e Cultura, v. 10, p. 228-230, 1961/1962b.

RAGo, Margareth. Do cabaréa lar - a utopia da cidade disciplinar. Rio de Janeiro: Paz e Terra, 1985.

RÁPIDA visão de conjunto, do panorama brasileiro em que a CNER atua. Revista da Campanha Nacional de Educação Rural, Rio de Janeiro: Ministério da Educação e Cultura, v. 8, p. 284-290, 1959.

Regulamentação definitiva e fundo especial para a CNER. Revista da Campanha Nacional de Educação Rural, Rio de Janeiro: Ministério da Educação e Cultura,v. 3, p. 10-14,1º sem. 1956. Silva, Severino Pereira da. O êxodo em função das condições do meio rural. Revista da Campanha Nacional de Educação Rural, Rio de Janeiro: Ministério da Educação e Cultura, v. 3, p. $128-135,1^{\circ}$ sem. 1956.

SouzA, Luiz Rogério de. A missão rural, fator de recuperação do homem do campo. Revista da Campanha Nacional de Educação Rural, Rio de Janeiro: Ministério da Educação e Cultura, v. 1, p. 42-56, 1954.

. A missão rural e a escola primária. Revista da Campanba Nacional de Educação Rural, Rio de Janeiro: Ministério da Educação e Cultura, v. 4, p. 90-91,2º sem. 1956.

TANuri, Leonor Maria. História da formação de professores. Revista Brasileira de Educação, Rio de Janeiro: ANPEd; Campinas: Autores Associados, n. 14, p. 61-88, maio/ago. 2000.

Telles, José Francisco de Sá. Escola rural e seus problemas. Revista da Campanha Nacional de Educação Rural, Rio de Janeiro: Ministério da Educação e Cultura, v. 1, p. 57-74, 1954.

Um relatório técnico trimestral de Missão Rural da CNER do estado da Bahia. Revista da Campanha Nacional de Educaşão Rural, Rio de Janeiro: Ministério da Educação e Cultura, v. 4, p. 36-54, 20 sem. 1956.

UnidADEs didáticas no programa das diversas disciplinas dos cursos de treinamentos de professoras rurais. Revista da Campanha Nacional de Educação Rural, Rio de Janeiro: Ministério da Educação e Cultura, v. 10, p. 99-130, 1961/1962.

Xavier, Renato de Almeida. O ensino por demonstração. Revista da Campanba Nacional de Educação Rural, Rio de Janeiro: Ministério da Educação e Cultura, p. 112-115, 1º sem. 1956.

\section{SOBRE A AUTORA}

Iraíde Marques de Freitas Barreiro é doutora em educação pela Universidade de São Paulo (USP). Professora da Universidade Estadual Paulista (UNESP-Assis).

E-mail: iraide@assis.unesp.br

Recebido em agosto de 2012 Aprovado em dezembro de 2012 


\section{IRAIIDE MARQUES DE FREITAS BARREIRO}

\section{Formação para o ensino agrícola nos Centros de Treinamento de Professores e de Auxiliares Rurais (1952-1963)}

Este artigo analisa o ensino agrícola proposto e desenvolvido pela Campanha Nacional de Educação Rural (1952-1963) nos Centros de Treinamento de Professores e de Auxiliares Rurais. São analisados os programas de ensino desses cursos publicados no volume especial, número 10, editado pela Campanha em 1961/1962. O ensino agrícola compunha a educação rural e objetivava formar professoras rurais e ampliar conhecimentos do homem do campo para fixá-lo no seu meio. Essa formação buscou suprir a falta de professores rurais, de conhecimentos agrícolas, higiene rural, fortemente orientada pela "educação dos costumes", de como portar-se à mesa e valorização do lazer racional, a par de campanhas de registro civil e casamentos, campanha das árvores, incentivo para eleger representantes às diretorias como formas de educação para a cidadania. A ausência de professoras rurais e os baixos salários denunciados desnudam as práticas de nossos atuais governantes ao desvalorizarem a profissão docente.

Palavras-chave: ensino agrícola; educação rural; formação de professores rurais.

\section{Training for agricultural education in the Training Centers for Rural Teachers and Assistants (1952-1963)}

This paper analyzes agricultural education as proposed and developed by the National Campaign for Rural Education (1952-1963) in Training Centers for Rural Teachers and Assistants. It analyzes the curricula of such courses published by the campaign in special issue, number 10 in 1961/1962. Agricultural education was a part of rural education and aimed to train rural teachers and expand the knowledge of rural men to make them remain in their environment. This training aimed to address the shortage of rural teachers, of agricultural knowledge, rural hygiene, strongly guided by the "education of manners", of how to behave at the table and by the appreciation of rational leisure, together with campaigns for civil and marriage registration, a campaign for trees, encouragement to elect representatives to boards as a means of educating for citizenship. Such lack of rural teachers and the complaints about low wages disclose the practices of our current rulers who devalue the teaching profession.

Keywords: agricultural education; rural education; training for rural teachers. 


\section{Formación para la enseñanza agrícola en los Centros de Entrenamiento de Profesores y Auxiliares Rurales (1952-1963)}

Este artículo analiza la enseñanza agricola propuesta y desarrollada por la Campaña Nacional de Educación Rural (1952-1963) en los Centros de Entrenamientos de Profesores y Auxiliares Rurales. Se analizan los programas de enseñanza de esos cursos publicados en el volumen espacial, número 10, editado por la Campaña en 1961/1962. La enseñanza agricola componía la educación rural y tenía como objetivo formar profesoras rurales y ampliar conocimientos del hombre del campo para estabilizarlo en su medio. Esa formación buscó suplir la falta de profesores rurales, de conocimientos agricolas, higiene rural, fuertemente orientada por la "educación de las costumbres", de como portarse a la mesa y la valoración del ocio racional, así como campañas de registro civil y casamientos, campaña de los árboles, incentivo para elegir representantes de los directorios como forma de educación para la ciudadanía. La ausencia de profesoras rurales y los bajos sueldos denunciados desnudan las prácticas de desvalorización docente de nuestros gobernantes.

Palabras clave: enseñanza agrícola; educación rural; formación de profesores rurales. 